\title{
HABLA PRIVADA EN LOS MENSAJES DE NIÑAS Y NIÑOS BILINGÜES Y MONOLINGÜES
}

\section{PRIVATE SPEECH IN THE MESSAGES OF BILINGUAL AND MONOLINGUAL CHILDREN}

\author{
CONCHI SAN MARTÍN MARTÍNEZ \\ Universidad de Barcelona. Barcelona, España \\ conchasanmartin@ub.edu \\ HUMBERT BOADA CALBET \\ Universidad de Barcelona. Barcelona, España \\ hboada@ub.edu \\ MARIA FORNS SANTACANA \\ Universidad de Barcelona. Barcelona, España \\ mforns@ub.edu
}

\section{RESUMEN}

En este trabajo se estudian los posibles vínculos entre la presencia de marcadores de reflexión y el desempeño comunicativo de niñas y niños bilingües y monolingües mientras realizan una tarea referencial. Los marcadores reflexivos se conceptualizan al modo vygotskiano como habla privada, y se operativizan en base a la noción de fragmentación informativa. Se realiza un estudio longitudinal con 24 parejas de niñas y niños a los cuatro y seis años, y empleando una metodología observacional. Los resultados muestran divergencias y similitudes en el empleo habla privada en función del grupo lingüístico. A los seis años el grupo bilingüe que realiza la prueba en su lengua materna (bilingüe moderado) es el que presenta más habla privada, mientras que el grupo bilingüe que no realiza la prueba en su lengua materna (bilingüe total) es el que presenta menor frecuencia. De forma paralela se observa una mejor calidad de los mensajes en el grupo bilingüe moderado y el monolingüe, y peor en el bilingüe total. Entre las similitudes se encuentra que la dificultad del referente favorece la emergencia de habla privada en todos los grupos lingüísticos. En síntesis, si la tarea excede las competencias infantiles se dificulta el proceso reflexivo, sin embargo este proceso puede retomarse tan pronto se crea una situación favorecedora en términos de control comunicativo y cognitivo. Como conclusión se apunta que el habla privada tiene un papel relevante en el desarrollo comunicativo bilingüe que parece de utilidad poder explorar.

Palabras clave: Bilingüismo, habla privada, comunicación referencial, Vygotsky, autorregulación. 


\begin{abstract}
This research examines the possible links between the presence of reflection markers and children's bilingual and monolingual communicative performance while carrying out a referential task. Reflection markers are conceptualized in a Vygotskian manner as private speech, and they are operationalized by the notion of informative fragmentation. A longitudinal study was conducted with 24 pairs of girls and boys, aged four to six years, using observational methodology. The results show some divergence and similarities in the use of private speech as a function of linguistic group. At age six, the bilingual group performing the test in their mother tongue (moderate bilingual) presents more private speech, whereas the bilingual group that does not perform the test in their mother tongue (total bilingual) displays lower frequency of private speech. Messages of better quality were observed in the moderate bilingual and monolingual groups, and poorer quality in the total bilingual group. Among the similarities is the fact that the difficulty of the referent promotes the emergence of private speech in all the linguistic groups. In synthesis, if the task exceeds children's competence, the reflexive process is impaired, but this process can be regained as soon as a favorable situation is created in terms of communicative and cognitive control. It is concluded that private speech plays a relevant role in bilingual communicative development, an aspect that seems useful to explore.
\end{abstract}

Keywords: Bilingualism, private speech, referential communication, Vygotsky, self-regulation.

Recibido: 28/11/12. Aceptado: 30/01/2013.

\title{
INTRODUCCIÓN
}

T a noción de habla privada alude a aquellas producciones verbales que niñas y niños emplean para comunicarse consigo mismas/os y que resultan identificables desde las edades preescolares. Vygotsky (1993[1934]) es el primer autor en interpretar esta habla autodirigida como instrumento de reflexión y autorregulación de las acciones. A través de esta habla la niña/o puede, en el transcurso de una tarea, rectificar la acción en curso, recordar lo hecho anteriormente, planificar lo que hará, etc. (Berk, 1992). Por ejemplo, durante la realización de un puzzle un niño, tras haber intentado encajar una pieza que no es adecuada, puede acabar desechándola y decir en voz baja "ahora redonda" al tiempo que selecciona otra pieza de entre las que tiene disponibles.

En base a estos planteamientos se ha originado una línea investigadora sobre el destino, desarrollo y función del habla privada, proporcionándose en líneas generales un apoyo empírico a la interpretación vygotskiana. La función de autorregulación se constata en la medida en que la cantidad de habla privada se 
incrementa con la aparición de dificultades y conflictos en la realización de una tarea (Fernyhough y Fradley, 2005), siempre y cuando estas dificultades no excedan (por exceso o por defecto) los niveles de competencia individuales (Montero y De Dios, 2006). También se documenta el desarrollo de características propias de esta habla tales como la fragmentación informativa así como una progresiva interiorización hacia formas encubiertas (e.g., murmullos) o silenciosas (Díaz y Berk, 1992; Winsler, Fernyhough y Montero, 2009 para revisiones).

En la actualidad se dispone de abundante información acerca de cómo el habla privada ayuda en la autorregulación de tareas diversas, principalmente tareas que implican la resolución individual de algún problema (e.g, clasificación categorial, resolución de puzzles, etc.). Sin embargo, ha sido de manera reciente que se ha planteado el estudio de esta habla en la regulación de tareas comunicativas (Fernyhough y Fradley, 2005, Feigenbaum, 2009; San Martín, Boada y Forns, 2009 para una revisión). En estos trabajos se explora si el habla privada ayuda a seleccionar, planificar o monitorizar los contenidos comunicativos cuando se elaboran mensajes dirigidos a un/a interlocutor/a. La tarea comunicativa que se ha empleado es la comunicativo referencial, en esta tarea se propone que una persona, en el rol de emisor, elabore un mensaje que describa las características de una serie de objetos referentes. Dicho mensaje debe posibilitar que un interlocutor, en el rol de receptor, identifique correctamente dichos objetos (Dickson, 1981; Resches y Pérez-Pereira, 2007). En estas tareas se documenta que la capacidad de elaborar mensajes no ambiguos por parte del emisor (esfera comunicativa pública) está relacionada con la emergencia de elementos de autorregulación de la tarea comunicativa o habla privada (esfera privada). A su vez el habla privada se incrementa si el/la niño/a encuentra dificultades o conflictos al elaborar mensajes dirigidos al receptor -e.g., por la dificultad de los referentes a ser comunicados (Boada y Forns, 2004; San Martín, Boada y Feigenbaum, 2011; Varenne y Beaudichon, 1996).

Los indicadores empíricos empleados para la identificación del habla privada en tareas comunicativas han sido variados. Principalmente se ha considerado la presencia de ciertos tipos de disfluencias, formulaciones en voz baja y silencios dentro de los mensajes como expresión de habla privada (Frawley y Lantolf, 1985; Lantolf, 2003; San Martín et al., 2011; Varenne y Beaudichon, 1996). También se ha considerado la presencia de cierto tipo de fragmentaciones informativas en los mensajes (Boada y Forns, 2004; San Martín, 2012). En este trabajo se adoptará esta segunda vía de identificación empírica, por lo que se expone en más profundidad. Trabajos como los de Centeno-Cortés y Jiménez (2004), Ramírez (1992) y Wertsch (1985) muestran que las fragmentaciones observadas en el contenido del habla privada no son azarosas y deben entenderse en relación al proceso de dominio cognitivo de la tarea. Así aquello que resulta más conflictivo cognitivamente suele quedar explícitamente verbalizado mientras que se fragmenta y queda implícito aquello menos conflictivo. Boada y Forns (2004) aplican esta noción a una situación comunicativa 
referencial. En un estudio longitudinal con niñas y niños a los cuatro y seis años, los citados autores identifican un tipo específico de mensaje como una forma particular del habla privada por sus características de fragmentación. Para argumentar esta cuestión conviene tener presente que, en la situación referencial analizada, enunciar un mensaje de calidad requiere conjugar dos aspectos: la denotación del objeto y la localización espacial del mismo. La denotación hace referencia a la identificación de los atributos necesarios para distinguir a un objeto de otro (e.g., según el color o tamaño). La localización hace referencia a las relaciones espaciales que pueden ser de soporte y de proximidad. Las relaciones de soporte expresan la localización del referente a través del contacto entre los objetos (e.g., "la pelota está en el suelo"). Las relaciones de proximidad, relativas por naturaleza, expresan aspectos de la localización en que el contacto físico entre objetos no queda manifiesto (e.g., "la pelota está a la izquierda"). Los citados autores señalan cómo bajo determinadas circunstancias las y los niños formulan un tipo de mensaje, denominado mínimo relacional, que contiene información fragmentada de manera que incluye una correcta denotación y expresión de la relación de proximidad, pero obvía la relación de soporte (e.g., el niño indica que "el gato está a la izquierda" sin verbalizar que está en el suelo). Estos mensajes se incrementan entre los cuatro y seis años y resultan más frecuentes en los referentes más difíciles. Este hallazgo contraviene lo esperado dado que diversos estudios muestran que las estructuras de soporte se dominan desde los cuatro años y se comprenden más fácilmente que las de proximidad (Bowerman, 1989; Plumert, Ewert y Spear, 1995). El hecho de que en los mensajes mínimo relacionales se exprese la información más difícil cognitivamente (relaciones de proximidad) y sin embargo la información más fácilmente accesible (relaciones de soporte) quede implícita u obviada, se interpreta como una forma de fragmentación indicadora de habla privada. La utilidad del empleo de los mensajes con este tipo de fragmentaciones como indicadores empíricos de habla privada en tareas comunicativas referenciales espaciales ha sido recientemente confirmada por San Martín (2012).

Un aspecto prácticamente inexplorado en el estudio de la regulación comunicativa a través de la noción del habla privada es el rol de esta habla en la realización de tareas comunicativas por parte de niñas y niños bilingües. Si bien inicialmente el bilingüismo se consideraba una potencial fuente de distorsión psicológica (BIE Luxembourg Conference, 1928), el grueso de la investigación realizada hasta la fecha muestra que la actuación lingüística de los bilingües y monolingües se sitúa en niveles equivalentes, planteándose que la condición de bilingüismo puede favorecer ciertos aspectos del desarrollo metalingüístico y metacognitivo (Meisel, 2004). Bialystok $(2001,2004)$ muestra, de manera particular, los efectos favorecedores del bilingüismo en la toma de conciencia metalingüística tal y como también indicaban Yelland, Pollard y Mercuri (1993), en relación a la toma de conciencia del significado de las palabras. En el terreno del desarrollo comunicativo, algunos estudios sugieren que la condición de bilingüismo plantea un conflicto cognitivo 
que influencia de manera diferencial a bilingües y monolingües (Forns y Boada, 1997). En esta línea, sería esperable que el habla privada tuviera un papel relevante y específico en el desarrollo comunicativo bilingüe.

Trabajos como los de Saville-Troike (1988) y Díaz, Padilla y Weathersby (1991) han sido pioneros en interrogarse sobre las relaciones entre empleo del habla privada y bilingüismo. Saville-Troike (1988) observa una pequeña muestra de niños/as chinos, coreanos y japoneses de entre 3 y 9 años, que están adquiriendo el inglés como segunda lengua. Encuentra que el habla privada aparece en la denominada fase silenciosa de la adquisición de la segunda lengua y está asociada a la práctica individual de la segunda lengua (e.g., repetición de ciertas verbalizaciones). Díaz et al. (1991) observa a niñas y niños bilingües español-inglés mientras realizan diversas tareas de forma individual, e identifica elementos de habla privada entre los 3 y 5 años. Este habla se incrementa con la dificultad de la tarea, y se interioriza gradualmente (eg., bajo la forma de murmullos). Los citados estudios sugieren que el habla privada está facilitando la toma de conciencia metalingüística en los bilingües y, a su vez, que el desarrollo y función de la misma sigue un patrón equivalente al de los monolingües. Sin embargo, esta línea investigadora se ha desarrollado en torno a tareas no comunicativas -e.g., el estudio de Díaz et al., (1992) observa el habla de las niñas y niños mientras resuelven, de manera individual, tareas de clasificación, reproducción de bloques y ordenación de una secuencia de acciones en una historia. Es por ello que queda abierto el interrogante sobre el rol del habla privada en las tareas comunicativas desempeñadas por niñas/os bilingües, por ejemplo, mientras se elaboran mensajes dirigidos a un interlocutor/a.

Considerando lo expuesto, el objeto de la presente investigación se cifra en el estudio de la actividad autorreguladora de niñas y niños bilingües y monolingües durante el desempeño de una tarea comunicativa referencial. Esta actividad autorreguladora se explora bajo la noción del habla privada vygotskiana y, en unas franjas de edad donde, según la literatura, es más probable su emergencia. Este estudio se establece considerando a su vez lo que ocurre en el desempeño comunicativo de bilingües y monolingües, esto es, en la esfera pública. De esta forma se pretende analizar:

a) Las similitudes y divergencias que pueden establecerse en la emergencia y evolución del habla privada -expresada bajo la forma de mensajes fragmentados mínimo relacionales- entre niñas y niños bilingües y monolingües de edades preescolares y primeras edades escolares,

b) Las variaciones del comportamiento comunicativo de bilingües y monolingües, en función de la calidad de los mensajes.

c) El papel del conflicto cognitivo generado bien por la dificultad del referente a comunicar, bien por el hecho de desempeñar la tarea en una condición lingüística bilingüe, esto es, de mayor complejidad frente a la monolingüe. 


\section{MÉTODO}

\section{Participantes}

Los participantes son 48 niñas y niños (54.83\% niñas y $45.16 \%$ niños) que provienen de dos escuelas de educación infantil en Barcelona. Estas niñas y niños pertenecen a familias de bajo nivel socioeconómico (tal y como señala Byalistok (2001) es importante consignar la clase social para contextualizar los aspectos sociales del bilingüismo). Su lengua materna es el castellano, y asisten -por decisión familiar- bien a un programa escolar cuya lengua vehicular y de contenidos es el castellano, bien a un programa de inmersión escolar cuya habla vehicular y de contenidos es el catalán. El nivel cognitivo y lingüístico de las y los participantes se analiza a los cuatro años mediante la adaptación castellana del test McCarthy (1983). Se opta por el empleo del índice cognitivo general de este test dado que incluye subescalas para la valoración de habilidades verbales, de razonamiento y relativas a la cuantificación, y se obtiene un índice de $101.54(S D=15.75)$, dentro de los estándares promedio poblacionales.

\section{Diseño}

Se adopta un diseño longitudinal de forma que las y los niños son evaluados por vez primera a los cuatro años $(M=4.5$ años; $S D=2.26)$, mientras están en el ciclo de educación infantil preescolar, y reevaluados dos años más tarde, a los seis años $(M=6.5$ años; $S D=2.26)$ cuando ya asisten al ciclo de educación escolar primaria. Se les agrupa en 24 parejas para llevar a término la tarea comunicativa. Dichas parejas se conforman de acuerdo a los criterios del profesorado sobre la relación entre las y los niños y su grado de participación en el aula. Los roles de emisor y receptor se asignan al azar al inicio de la prueba.

Se consideran dos elementos: a) el programa lingüístico escolar al que acuden las y los niños (programa regular monolingüe en castellano o programa de inmersión en catalán) y, b) la lengua empleada por el instructor adulto durante la aplicación de la tarea comunicativa (castellano o catalán). Estos elementos permiten formar tres grupos lingüísticos de ocho parejas cada uno. Un grupo queda constituido por parejas de niñas y niños que participan en el programa escolar regular y a quienes se les presenta la tarea en su lengua materna (condición monolingüe). El segundo grupo está constituido por niñas y niños que participan en el programa de inmersión lingüística en catalán y donde el instructor que presenta y guía la tarea comunicativa emplea el castellano (condición bilingüe moderada). El tercer grupo está constituido por niñas y niños que participan en el programa de inmersión lingüística y donde el instructor que presenta y guía la tarea comunicativa 
emplea el catalán (condición bilingüe total). Esta última condición se entiende que es más compleja en términos de control cognitivo y comunicativo.

\section{Material}

Se utiliza la tarea "Organización de una sala” diseñada por Boada y Forns (1997). El material empleado incluye dos láminas y un conjunto de ocho objetos referentes. La lámina del emisor muestra una mesa, una estantería y ocho objetos en unas localizaciones determinadas: dos tazas, una grande y roja y otra pequeña y verde, ubicadas en la estantería, dos botellas (una verde encima de la mesa y una rosa en el suelo al lado izquierdo de la mesa), un sombrero encima de la mesa hacia la izquierda, una pelota debajo de la mesa, y dos gatos, uno grande y otro pequeño, juntos al lado derecho de la mesa. La lámina del receptor sólo contiene el dibujo de una mesa y de una estantería. El receptor dispone de los ocho objetos, como figuras movibles, sin que estén ubicados en la lámina.

\section{Procedimiento}

El procedimiento seguido se basa en el creado por Krauss y Glucksberg (1969), en el que las personas participantes se sientan frente a frente pero separadas por una pantalla opaca que evita que tengan contacto visual. En la tarea "Organización de una sala" un adulto se sienta con la pareja de niños para mantener el canal comunicativo abierto y ayudar a mantener el desarrollo de la tarea. La tarea fue registrada en video, transcrita y codificada de acuerdo a un sistema de categorías validado previamente por Boada y Forns (2004).

\section{Tarea}

El emisor tiene que describir la localización de los objetos en la lámina y el receptor tiene que ubicar, ateniéndose a esas descripciones, los objetos en su lámina. Se pretende que las láminas resultantes sean idénticas al final de la tarea. Se anima a las y los niños a preguntar a su interlocutor/a si tienen dudas sobre dónde ubicar los objetos.

\section{Análisis}

Se analizan los siguientes elementos: a) calidad de los mensajes considerando la denotación del referente y la descripción de su localización, b) presencia de un tipo concreto de mensajes, mínimo relacionales, como indicadores de habla privada y, c) dificultad cognitiva del referente respecto a los que se formulan los mensajes. 


\section{a) Calidad de los mensajes}

La unidad de categorización es el mensaje definido como aquellas verbalizaciones del emisor cuyo contenido está relacionado con la identificación y localización de un objeto referente. La denotación hace referencia a la identificación verbal del referente mediante su nombre y los posibles atributos necesarios para distinguirlo de otros referentes presentes (e.g., según el color o tamaño). La localización de los referentes supone la expresión verbal de las relaciones espaciales de soporte y proximidad. Las relaciones de soporte se refieren a la descripción de la localización del objeto relativa a alguna estructura de soporte físico (encima o debajo de la mesa, la estantería o el suelo). Las relaciones de proximidad incluyen la descripción de localizaciones en que el contacto físico entre los objetos no es manifiesto, y en relación a ciertas coordinadas espaciales (a la derecha, centro o izquierda). En base a si los mensajes contienen o no los elementos de denotación y localización necesarios se construye una tipología de mensajes (ver Tabla I).

Tabla I. La calidad de los mensajes y el habla privada (adaptado de Boada y Forns, 2004).

\begin{tabular}{|l|l|l|}
\hline TIPOS DE MENSAJE & ELEMENTOS DEL MENSAJE & EJEMPLOS \\
\hline Mínimo & $\begin{array}{l}\text { Incluye únicamente información } \\
\text { sobre la denotación del referente o } \\
\text { información incompleta sobre su } \\
\text { relación de soporte. }\end{array}$ & $\begin{array}{l}\text { Pon la taza grande } \\
\text { (denotación) allí }\end{array}$ \\
\hline $\begin{array}{l}\text { Mínimo relacional } \\
\text { fragmentado }\end{array}$ & $\begin{array}{l}\text { Contiene información sobre la } \\
\text { denotación del referente y su } \\
\text { relación de proximidad. Se deja } \\
\text { implícita la información sobre la } \\
\text { relación de soporte. }\end{array}$ & $\begin{array}{l}\text { La taza grande } \\
\text { (denotación) a la derecha } \\
\text { (relación de proximidad) }\end{array}$ \\
\hline Básico & $\begin{array}{l}\text { Contiene información sobre la } \\
\text { denotación del referente y su } \\
\text { relación de soporte. }\end{array}$ & $\begin{array}{l}\text { La taza grande } \\
\text { (denotación) en la } \\
\text { estantería (relación de } \\
\text { soporte) }\end{array}$ \\
\hline Completo & $\begin{array}{l}\text { Contiene información sobre } \\
\text { la denotación del referente, } \\
\text { la relación de soporte y de } \\
\text { proximidad. }\end{array}$ & $\begin{array}{l}\text { La taza grande } \\
\text { (denotación) en la } \\
\text { estantería (relación de } \\
\text { soporte), arriba (relación } \\
\text { de proximidad 1) a la } \\
\text { derecha (relación de } \\
\text { proximidad 2) }\end{array}$ \\
\hline
\end{tabular}

b) Mensajes minimo relacionales como expresión de habla privada

Siguiendo la línea de trabajos realizada por Boada y Forns (2004), Centeno-Cortés 
y Jiménez (2004), Ramírez (1992) y Wertsch (1985) se considerará la presencia de determinados tipos de fragmentaciones en los mensajes como expresión de habla privada. Concretamente el habla privada se operativiza a través de la identificación de mensajes mínimo relacionales, es decir aquéllos donde se observa el siguiente tipo de fragmentación: se expresa verbalmente la denotación del referente y las relaciones de proximidad mientras que las relaciones de soporte quedan no verbalizadas (ver Tabla I).

\section{c) Dificultad cognitiva del referente}

La dificultad del referente se operativiza en función de la cantidad de información necesaria para su identificación y localización. Hay referentes cuya identificación únicamente requiere nombrar el objeto, mientras que otros requieren nombrar además algún atributo distintivo respecto de otros objetos presentes (e.g., la botella puede ser la verde o la rosa). Hay referentes que requieren una única relación de soporte y proximidad para ser localizados mientras que otros requieren que se verbalicen varias de estas relaciones para ser ubicados correctamente (e.g., la taza pequeña está en la estantería pero debe indicarse si está en el estante de arriba o de abajo y si está a la derecha o a la izquierda). Todo ello permite distinguir entre dos tipos de referentes: con baja dificultad (sombrero, botella verde y pelota) y con alta dificultad cognitiva (tazas, gatos y botella rosa).

\section{RESULTADOS}

Se identifican un total de 497 mensajes producidos por las niñas y niños a los cuatro años y un total de 518 elaborados a los seis años. Los resultados se exponen a través de los siguientes ejes: a) distribución del habla privada en los mensajes según la edad y el grupo lingüístico; b) calidad de los mensajes en relación a la edad y el grupo lingüístico; y c) habla privada y calidad de los mensajes en los referentes difíciles: distribución en relación a la edad y del grupo lingüístico.

\section{a) Empleo de habla privada en los mensajes, edad y grupo lingüistico}

En la Tabla II se recoge la distribución de los mensajes en función de si contienen o no habla privada, de la edad y del grupo lingüístico. En un primer momento del análisis la consideración de los mensajes sin habla privada se ha realizado de manera global, mediante sumatoria de mensajes erróneos, básicos y completos. Los mensajes con habla privada fueron, considerando conjuntamente los tres grupos, más frecuentes a los seis años $(25.38 \%$ del total de mensajes elaborados a esta edad) comparados con los emitidos a los cuatro años $(10.87 \%$ del total de 
mensajes elaborados a esta edad). Para cada grupo lingüístico se detecta un incremento entre los cuatro y seis años: $\chi^{2}(1, n=352)=6.80, p<.01$, en el grupo de monolingües; $\chi^{2}(1, n=342)=27.68, p<.01$ en el grupo de bilingües moderados; $\chi^{2}(1, n=321)=53.97, p<.01$ en el grupo de bilingües totales.

A los cuatro años se observa que no hay diferencias significativas entre el grupo lingüístico y la presencia o no de habla privada en los mensajes. Sin embargo dos años más tarde sí aparecen diferencias que pueden considerarse significativas, $\chi^{2}$ $(2, \mathrm{n}=518)=5.82, p=.054$, de forma que en el grupo bilingüe moderado se detecta una mayor presencia de mensajes con habla privada mientras que en el grupo bilingüe total se detecta una menor presencia de mensajes con este habla.

Tabla II. Edad, grupo lingüístico y empleo de habla privada en los mensajes. Porcentaje y (frecuencia).

\begin{tabular}{|c|c|c|c|c|c|}
\hline \multirow[b]{2}{*}{ Edad } & \multirow[b]{2}{*}{\begin{tabular}{|l|} 
Habla privada \\
(HP) en mensajes
\end{tabular}} & \multicolumn{3}{|c|}{ Grupo lingüístico } & \multirow[b]{2}{*}{ Total } \\
\hline & & Monolingüe & \begin{tabular}{|l} 
Bilingüe \\
moderado
\end{tabular} & $\begin{array}{l}\text { Bilingüe } \\
\text { total }\end{array}$ & \\
\hline \multirow{3}{*}{$\begin{array}{l}4.5 \text { años } \\
\mathrm{N}=24\end{array}$} & Sin HP & $28.97(144)$ & $31.99(159)$ & $28.17(140)$ & $89.13(443)$ \\
\hline & $\begin{array}{l}\text { Con HP (mínimo } \\
\text { relacional) }\end{array}$ & $4.83(24)$ & $2.62(13)$ & $3.42(17)$ & $10.87(54)$ \\
\hline & Total & $33.8(168)$ & $34.61(172)$ & $31.59(157)$ & $100(497)$ \\
\hline \multirow{3}{*}{$\begin{array}{l}6.5 \text { años } \\
N=24\end{array}$} & Sin HP & $26.25(136)$ & $22.97(119)$ & $25.48(132)$ & $74.71(387)$ \\
\hline & $\begin{array}{l}\text { Con HP (mínimo } \\
\text { relacional) }\end{array}$ & $9.27(48)$ & $10.04(52)$ & $5.98(31)$ & $25.28(131)$ \\
\hline & Total & $35.52(184)$ & $32.81(170)$ & $31.66(164)$ & $100(518)$ \\
\hline
\end{tabular}

\section{b) Calidad de los mensajes en función de la edad y del grupo lingüistico}

En la Tabla III se recoge la distribución de los mensajes en función de su calidad, la edad y el grupo lingüístico.

La prueba de $\chi^{2}$ muestra que la calidad de los mensajes varía de forma significativa en función del grupo lingüístico a los cuatro años, $\chi^{2}(6, n=497)=40.97, p$ $<.001$, y a los seis años, $\chi^{2}(6, n=518)=29.74, p<.01$. A su vez, para cada grupo lingüístico se detectan diferencias significativas de la calidad de los mensajes en función de la edad: $\chi^{2}(3, n=352)=71.10, p<.01$, en el grupo monolingües; $\chi^{2}$ $(3, n=343)=77.22, p<.01$, en el grupo bilingüe moderado, y $\chi^{2}(3, n=320)=$ $61.35, p<.01$, en el grupo bilingüe total. 
Tabla III. Edad, grupo lingüístico y calidad de los mensajes. Porcentaje y (frecuencia).

\begin{tabular}{|c|c|c|c|c|c|c|}
\hline \multirow[t]{2}{*}{ Edad } & \multirow[t]{2}{*}{$\begin{array}{l}\text { Grupo } \\
\text { Lingüístico }\end{array}$} & \multicolumn{3}{|c|}{$\begin{array}{c}\text { Calidad de mensajes } \\
\text { (sin habla privada) }\end{array}$} & \multirow{2}{*}{$\begin{array}{l}\text { Mínimo } \\
\text { Relacional } \\
\text { (fragmentado) }\end{array}$} & \multirow[t]{2}{*}{ Total } \\
\hline & & Mínimo & Básico & Completo & & \\
\hline \multirow{4}{*}{$\begin{array}{l}4.5 \text { años } \\
N=24\end{array}$} & Monolingue & $6.64(33)$ & $19.72(98)$ & $2.62(13)$ & $4.83(24)$ & $33.81(168)$ \\
\hline & $\begin{array}{l}\text { Bilingüe } \\
\text { moderado }\end{array}$ & $4.83(24)$ & $25.96(129)$ & $1.21(6)$ & $2.62(13)$ & $34.62(172)$ \\
\hline & Bilingüe total & $11.27(56)$ & $13.68(68)$ & $3.22(16)$ & $3.42(17)$ & $31.59(157)$ \\
\hline & Total & $22.73(113)$ & $59.35(295)$ & $7.04(35)$ & $10.87(54)$ & $100(497)$ \\
\hline \multirow{4}{*}{$\begin{array}{l}6.5 \text { años } \\
N=24\end{array}$} & Monolingue & $1.35(7)$ & $11.58(60)$ & $13.32(69)$ & $9.27(48)$ & $35.52(184)$ \\
\hline & $\begin{array}{l}\text { Bilingüe } \\
\text { moderado }\end{array}$ & $2.32(12)$ & $12.36(64)$ & $8.30(43)$ & $10.04(52)$ & $33.01(171)$ \\
\hline & Bilingüe total & $0.77(4)$ & $17.76(92)$ & $6.95(36)$ & $5.98(31)$ & $31.46(163)$ \\
\hline & Total & $4.44(23)$ & $41.69(216)$ & $28.57(148)$ & $25.29(131)$ & $100(518)$ \\
\hline
\end{tabular}

$\mathrm{Al}$ respecto, de los mensajes más característicos de cada edad y grupo lingüístico cabe destacar que a los cuatro años, el tipo de mensaje predominante en los tres grupos es el de calidad básica. El grupo bilingüe total es el que muestra una mayor producción de mensajes de baja calidad, mensajes mínimos (11.27\%).

De manera global a los seis años se encuentra una disminución de los mensajes mínimos-siendo muy poco frecuentes en los tres grupos. También disminuyen los mensajes de calidad básica. Estas disminuciones son correlativas a un incremento del número de mensajes completos y de los fragmentados por habla privada. A esta edad el grupo monolingüe es el que elabora un mayor porcentaje de mensajes completos, en comparación a los otros grupos lingüísticos. Una comparativa de dos a dos entre los diferentes grupos muestra que en el grupo bilingüe moderado no se observan diferencias significativas en la calidad de los mensajes producidos respecto del grupo monolingüe, $\chi^{2}(3, n=355)=7.174, p=.066$. Sin embargo, los dos grupos bilingües sí muestran diferencias significativas en la calidad de los mensajes elaborados, $\chi^{2}(3, n=334)=14.77, p<.01$, detectándose en el grupo bilingüe total un mayor porcentaje de mensajes básicos y una menor presencia de mensajes mínimo relacionales.

c) Habla privada y calidad de los mensajes en los referentes difíciles: distribución en función de la edad y del grupo lingüistico

Se analiza en primer lugar la distribución del habla privada en los mensajes en relación a la dificultad de los referentes. Tal y como se recoge en la Tabla IV a los 
cuatro años de los 497 mensajes elaborados, 248 fueron sobre referentes de baja dificultad cognitiva y 249 sobre referentes de alta dificultad, representando respectivamente el $49.89 \%$ y $50.1 \%$ del total de mensajes elaborados. A los seis años, de los 518 mensajes elaborados, 224 mensajes fueron sobre referentes de baja dificultad y 294 sobre referentes de alta dificultad, representando respectivamente el $43.24 \%$ y $56.75 \%$ del total de mensajes elaborados.

Tabla IV. Habla privada y dificultad de los referentes.

Porcentaje y (frecuencia).

\begin{tabular}{|c|c|c|c|c|}
\hline \multirow{2}{*}{ Edad } & \multirow[b]{2}{*}{ Referente } & \multicolumn{2}{|c|}{ Habla privada (HP) en mensajes } & \multirow{2}{*}{ Total } \\
\hline & & Sin HP & Con HP & \\
\hline \multirow{3}{*}{$\begin{array}{l}4.5 \text { años } \\
N=24\end{array}$} & Fácil & $49.09(244)$ & $.80(4)$ & $49.90(248)$ \\
\hline & Difícil & 40.04 (199) & $10.06(50)$ & $50.10(249)$ \\
\hline & Total & $89.13(443)$ & $10.87(54)$ & $100(497)$ \\
\hline \multirow{3}{*}{$\begin{array}{l}6.5 \text { años } \\
N=24\end{array}$} & Fácil & $39.83(204)$ & $3.86(20)$ & $43.24(224)$ \\
\hline & Difícil & $35.33(183)$ & $21.43(111)$ & $56.76(294)$ \\
\hline & Total & $74.71(387)$ & $25.29(131)$ & $100(518)$ \\
\hline
\end{tabular}

Para cada grupo de edad se considera la distribución del habla privada en los mensajes en función del tipo de referente. Esta relación a los cuatro años resulta significativa, $\chi^{2}(1, n=497)=41.86, p<.01$, prácticamente todos los mensajes referidos a objetos de baja dificultad se elaboran sin habla privada, mientras que los mensajes referidos a objetos de alta dificultad muestran un mayor uso de habla privada respecto de los fáciles. Recordemos que, tal y como se indicó en el apartado de metodología, los objetos de alta dificultad requieren que se proporcione más cantidad de información para que puedan ser identificados y colocados en comparación a la información requerida para los referentes de baja dificultad.

La relación entre habla privada y tipo de referente también resulta significativa dos años más tarde, $\chi^{2}(1, n=518)=54.44, p<.01$, apareciendo de manera más acentuada: la mayoría de mensajes sobre referentes fáciles no contienen habla privada; en los referentes difíciles se muestra un mayor uso de habla privada respecto de los fáciles, y en comparación a dos años antes, se observa un incremento de los mensajes con habla privada sobre referentes difíciles (10.06\% a los 4 años frente a $21.43 \%$ a los seis años).

Se procede a continuación a focalizar los mensajes referidos a objetos de alta dificultad, analizando el habla privada y la calidad de dichos mensajes en función de la edad y del grupo lingüístico, aspectos recogidos en la Tabla V. 
Tabla V. Habla privada y calidad de los mensajes en los referentes difíciles en función de la edad y del grupo lingüístico. Porcentaje y (frecuencia).

\begin{tabular}{|l|l|l|l|l|l|l|}
\hline Edad & $\begin{array}{l}\text { Grupo } \\
\text { Lingüístico }\end{array}$ & Mínimo & Básico & Completo & $\begin{array}{l}\text { Mínimo Relac. } \\
(\text { Fragmentado })\end{array}$ & Total \\
\hline $\begin{array}{l}4.5 \\
\text { años } \\
\text { N=24 }\end{array}$ & Monolingüe & $8.84(22)$ & $12.05(30)$ & $4.02(10)$ & $9.43(21)$ & $20.67(83)$ \\
\cline { 2 - 8 } & $\begin{array}{l}\text { Bilingüe } \\
\text { moderado }\end{array}$ & $4.02(10)$ & $22.49(56)$ & $2.81(7)$ & $5.22(13)$ & $34.53(86)$ \\
\cline { 2 - 7 } & $\begin{array}{l}\text { Bilingüe } \\
\text { total }\end{array}$ & $12.45(31)$ & $8.03(20)$ & $5.22(13)$ & $6.43(16)$ & $32.12(80)$ \\
\cline { 2 - 7 } & Total & $25.31(63)$ & $42.57(106)$ & $12.04(30)$ & $20.08(50)$ & $100(249)$ \\
\hline \multirow{2}{*}{$\begin{array}{l}\text { años } \\
\text { año }\end{array}$} & Monolingüe & $1.02(3)$ & $5.78(17)$ & $15.31(45)$ & $13.95(41)$ & $36.05(106)$ \\
\cline { 2 - 7 } & $\begin{array}{l}\text { Bilingüe } \\
\text { moderado }\end{array}$ & $2.38(7)$ & $5.78(17)$ & $10.54(31)$ & $14.29(42)$ & $32.99(97)$ \\
\cline { 2 - 7 } & $\begin{array}{l}\text { Bilingüe } \\
\text { total }\end{array}$ & $0.34(1)$ & $11.22(33)$ & $9.86(29)$ & $9.52(28)$ & $30.95(91)$ \\
\cline { 2 - 7 } & Total & $3.74(11)$ & $22.78(67)$ & $35.71(105)$ & $37.75(111)$ & $100(294)$ \\
\hline
\end{tabular}

A los cuatro años los diferentes grupos lingüísticos muestran diferencias en la distribución de la calidad de los mensajes cuando elaboran mensajes sobre referentes difíciles, $\chi^{2}(6, n=249)=33.44, p<.01$. En el grupo monolingües el mensaje más frecuente es el básico y se aprecia una ligera mayor presencia de estos mensajes en comparación con los otros dos grupos. En el grupo bilingüe moderado el mensaje más frecuente es también el básico, mientras que en el grupo bilingüe total es el mínimo. A los seis años, también resulta significativa la relación entre grupo lingüístico y calidad de los mensajes, $\chi^{2}(6, n=294)=19.71, p<.01$. En el grupo monolingüe los mensajes más frecuentes son los mínimo relacionales y los completos. El grupo bilingüe moderado presenta una distribución de la calidad de los mensajes muy similar a la que presenta el grupo monolingüe. Sin embargo, el grupo bilingüe total presenta un bajo empleo de mensajes mínimo relacionales y un mayor empleo de mensajes básicos.

\section{DISCUSIÓN}

En este estudio longitudinal se ha pretendido analizar las similitudes y diferencias en la aparición del habla privada en las comunicaciones de niñas y niños bilingües y monolingües a los cuatro y seis años mientras desarrollan una tarea referencial. El elemento central de análisis de los intercambios comunicativos ha sido el tipo 
de mensaje elaborado por el niño o niña en el rol de emisor y se ha tomado como indicador de habla privada la presencia de un tipo concreto de fragmentaciones en los mensajes (mensajes mínimo relacionales) siguiendo las propuestas de Boada y Forns (2004).

Los resultados muestran una baja presencia de habla privada en los mensajes elaborados por las y los preescolares, de forma que en ningún grupo lingüístico llega a estar presente en más de un $5 \%$ del total. A su vez en esta edad los mensajes tienen una baja calidad, siendo mayoritarios aquéllos en que únicamente se identifica el referente y su localización de soporte (mensajes básicos). Con la edad el habla privada se incrementa de forma significativa y en todos los grupos lingüísticos, al tiempo que también se incrementa de manera general la calidad de los mensajes elaborados. Estos resultados son coincidentes con los obtenidos en otros estudios con franjas de edades similares y con empleo de este mismo indicador de habla privada (Boada y Forns, 2004; San Martín, 2012) u otros indicadores (Frawley y Lantolf, 1985; San Martín et al., 2011).

El aspecto novedoso del presente estudio es la consideración de posibles variaciones en el empleo del habla privada en función de si los/as niños/as están en uno de los tres grupos lingüísticos: el grupo monolingüe, el grupo bilingüe en condición de bilingüismo moderado y el grupo bilingüe en condición de bilingüismo total. A los cuatro años no se detectan diferencias significativas entre dichos parámetros, siendo el empleo del habla privada, tal y como se indicó anteriormente, escaso en los tres grupos lingüísticos. Dos años más tarde sí se encuentran estas diferencias, de forma que en el grupo bilingüe moderado se detecta un mayor empleo de habla privada respecto a los otros dos grupos, y en el grupo bilingüe total es donde aparece un menor uso de esta habla. Estos resultados se interpretan considerando el papel del conflicto cognitivo en la generación del habla privada y su relación dinámica con el nivel de competencia infantil. Son diversos los trabajos, en tareas comunicativas y no comunicativas, que muestran un incremento del habla privada cuando el/la niño/a encuentra conflictos o dificultades en el desarrollo de una tarea (e.g., Díaz et al., 1991; Fernyhough y Fradley, 2005; Montero y De Dios, 2006; San Martín et al., 2011; Varenne y Beaudichon, 1996). La consideración del bilingüismo como situación que favorece el conflicto es algo reseñado a nivel de investigación (Bialystok, 2001, 2004; Forns y Boada, 1997; Yelland et al., 1993). Ello puede resultar favorecedor de la activación de ciertos procesos cognitivos reflexivos, en este caso evidentes por la mayor emergencia del habla privada en la condición de bilingüismo moderado a los seis años. Ahora bien, siguiendo este razonamiento también cabría esperar que ello resultara visible en el grupo bilingüe total, cosa que no sólo no acontece sino que se observa la tendencia contraria. No resulta sencillo interpretar el porqué los dos grupos bilingües, con el mismo nivel cultural, socioeconómico y educativo, muestran estas diferencias tan acusadas. Las circunstancias sociales de control comunicativo y de representación cognitivas, 
introducidas por el lenguaje empleado por el experimentador adulto sugieren tener una importante influencia en la posibilidad de desarrollar y producir estrategias comunicativas (Forns y Boada, 1997). En este sentido, cabe recordar que la condición del grupo bilingüe total es más exigente cognitivamente que el resto, dado que el instructor adulto emplea una lengua que no es la lengua materna del niño/a. La realización de la tarea bajo estas condiciones parece estar superando los niveles de competencia infantiles, pudiendo resultar en exceso difícil cognitivamente dado el incremento en las demandas de procesamiento lingüístico. En estos casos, tal y como muestran investigaciones desarrolladas en tareas no comunicativas (Montero y De Dios, 2006), el habla privada quedaría inhibida o fracasaría en posibilitar la resolución de la tarea. Nuestros resultados parecen apoyar claramente esta línea interpretativa ahora ampliándola al terreno del dominio comunicativo.

La distribución de la calidad de los mensajes también varía en función del grupo lingüístico. A los cuatro años el mensaje básico es el característico en todos los grupos aunque en el grupo de bilingüismo total se observa una mayor presencia de mensajes de menor calidad (mensajes mínimos). Dos años más tarde se produce un incremento de la calidad de mensajes en todos los grupos lingüísticos y de nuevo se detectan diferencias significativas en la distribución de la calidad de los mensajes según el grupo lingüístico: el comportamiento comunicativo de los monolingües es muy parecido al de los bilingües moderado, con una importante presencia de mensajes completos, mientras que en el grupo de bilingües total, aparecen mensajes de menor calidad (mensajes básicos). El conjunto de estos resultados sugiere que la actuación comunicativa de los bilingües se asemeja a la del grupo de monolingües cuando las condiciones de control comunicativo les son favorables, esto es, cuando en el grupo bilingüe se presenta la tarea en la lengua materna. En contraste, en el grupo bilingüe total, donde la tarea se desarrolla en la lengua de escolarización, las niñas y niños elaboran mensajes de menor calidad a ambas edades, mostrando un peor desempeño comunicativo. Este peor desempeño en la esfera pública puede considerarse la otra cara de la menor autorregulación a través del habla privada, probablemente inhibida en el grupo bilingüe total tal y como se argumentó anteriormente. De esta forma la dinámica entre emergencia de indicadores de autorregulación (esfera privada) y calidad de los mensajes (esfera pública) ya observada en trabajos como el de San Martín (2012) queda ahora ampliada a la condición del bilingüismo.

Se contempla, a continuación, la otra fuente de conflicto cognitivo analizada, esto es, la complejidad de los referentes. Tanto a los cuatro como a los seis años, la aparición de formas privadas en los mensajes se incrementa cuando las niñas y niños elaboran mensajes sobre referentes difíciles y ello se acentúa a los seis años. Estas tendencias ya fueron documentadas por otras autoras y autores en tareas no comunicativas y comunicativas (e.g., los trabajos de Centeno-Cortés y Jiménez, 2004 sobre la adquisición de una segunda lengua por parte de adultos). La nove- 
dad que aquí se aporta es la constatación de este fenómeno en los diferentes grupos lingüísticos monolingües y bilingües y con una perspectiva longitudinal. La mayor demanda cognitiva que supone la tarea para los bilingües en condición de empleo de lengua no materna, y que acaba excediendo su nivel de competencia, queda de nuevo manifiesta en su comportamiento en la esfera pública y privada cuando formulan mensajes sobre referentes difíciles. La comparativa entre los tres grupos muestra que a los seis años el grupo monolingüe y el bilingüe en lengua materna producen más mensajes de naturaleza privada y de tipo completo. Sin embargo, las niñas y niños bilingües que desarrollan la tarea en lengua de escolarización no materna muestran estar menos avanzados en estos parámetros, emergiendo un comportamiento comunicativo muy similar al de las producciones típicas de los cuatro años: menor presencia de mensajes de carácter privado y mayor presencia de mensajes básicos.

Respecto de los trabajos pioneros de Díaz et al. (1991) o Saville-Troike (1988) se ha profundizado el estudio de las relaciones entre habla privada y bilingüismo en unas tareas, las comunicativas, no contempladas con anterioridad. En estas tareas los bilingües parecen entrar en un proceso de autorregulación y reflexión a través del habla privada donde se manifiestan no sólo similitudes sino también diferencias respecto a los monolingües. Estas diferencias son más marcadas entre los grupos lingüísticos a los 6 años, cuando el bilingüismo está más avanzado.

En base a los resultados obtenidos pueden apuntarse dos cuestiones sobre el estudio del habla privada y del bilingüismo en el contexto escolar, la primera es de carácter más teórico y la segunda de carácter más aplicado.

Siguiendo la línea de Bialystok (2001) la condición del bilingüismo implica ventajas cognitivas de diversa índole, muy especialmente relacionadas con una mayor flexibilización de los procesos ejecutivos atencionales. Sin embargo, estas ventajas no tienen por qué resultar evidentes desde el inicio sino que pueden irse mostrando progresivamente según la competencia y desempeño en ambas lenguas se va consolidando. Esta oscilación de las ventajas cognitivas en las etapas iniciales es a lo que apuntan los resultados obtenidos en el presente estudio, tanto en relación al éxito en la resolución de la tarea comunicativa (calidad de los mensajes elaborados) como en relación al uso del habla privada. Recordemos que las niñas y niños que están en un programa de inmersión bilingüe muestran un comportamiento divergente: el empleo de la lengua materna en la realización de la tarea comunicativa facilita su resolución y apoyo en el habla privada, mientras que cuando la tarea se presenta en la lengua no materna aparecen dificultades y un menor uso del habla privada. Así, puede resultar de interés para la profundización del desarrollo comunicativo bilingüe la inclusión de los planteamientos de Vygotsky (1993 [1934]) acerca del habla privada.

Desde un enfoque más aplicado, para las y los docentes la consideración del habla privada puede ser una herramienta valiosa cuando trabajan en contextos 
escolares donde se emplea una lengua de escolarización diferente a la materna. La identificación del habla privada permite detectar aquello cuyo dominio cognitivo está siendo problemático y desafiante para la niña o el niño, e implementar tareas que puedan ayudar a la progresiva consolidación del desarrollo bilingüe.

\section{REFERENCIAS}

Berk, Laura. E. (1992). Children's private speech: An overview of theory and the status of research. En R. M. Díaz y L. E. Berk (eds.), Private speech: From social interaction to self-regulation (pp. 17-53). Hillsdale, NJ: Erlbaum.

Bialystok, Ellen. (2001). Bilingualism in development: Language, literacy, and cognition. New York: Cambridge University Press.

Bialystok, Ellen. (2004). The impact of bilingualism on language and literacy development. En T. K. Bhatia, y W.C. Ritchie (eds.), The handbook of bilingualism (pp.577-601). MA: Blackwell Publishing.

BIE (1928). Bilinguisme et éducation. Travaux de la conférence internationale tenue à Luxembourg. Genève: Bureau International d'Éducation.

Boada, Humbert y Forns, María. (1997). Observational guidelines of communicative exchange: An ecological approach to referential communication. Anuario de Psicología, 75, 7-36.

Boada, Humbert y Forns, María. (2004). The cognitive complexity of the referent and self-regulation in children's messages. Journal of Psycholinguistic Research, 3, 237-261.

Bowerman, Melissa. (1989). Learning a semantic system: What role do cognitive predispositions play? En M. L. Rice y R. L. Schiefelbuch (eds.), The teachability of languages (pp.133-169). Baltimore: Brookes.

Centeno-Cortés, Beatriz y Jiménez, A. (2004). Problem solving task in a foreign language: The importance of the $\mathrm{L} 1$ in private speech thinking. International Journal of Applied Linguistics, 1, 7-35.

Díaz, Rafael M., Padilla, K.A. y Weathersby, E.K. (1991). The effects of bilingualism on preschoolers' private speech. Early Childhood Research Quarterly, 6, 377-393.

Díaz, Rafael M. y Berk, Laura E. (eds.). (1992). Private speech: From social interaction to self-regulation. Hillsdale, NJ: Erlbaum.

Dickson, W. Patrick (ed.). (1981). Children's oral communication skills. New York: Academic Press.

Feigenbaum, Peter. (2009). Development of communicative competence through private and inner speech. En A. Winsler, Ch. Fernyhough e I. Montero (eds.), Private speech, executive functioning, and the development verbal self-regulation (pp. 105-120). Cambridge: Cambridge University Press. 
Fernyhough, Charles y Fradley, Emma. (2005). Private speech on an executive task: Relations with task difficulty and task performance. Cognitive Development, 20, 103-120.

Forns, María y Boada, Humbert. (1997). Estudi longitudinal de la reestructuració del missatge en nens bilingües i monolingües dins d'un programa d'immersió lingüística. [Longitudinal study of message re-estructuration in bilinguals and monolinguals children submitted to immersion linguistic program]. Anuario de Psicología, 75, 77-93.

Frawley, William y Lantolf, James P. (1985). Second-language discourse: A Vygotskyan perspective. Applied Linguistics, 6, 19-44.

Krauss, R. M. y Glucksberg, S. (1969). The development of communication: Competence as a function of age. Child Development, 40, 255-256.

Lantolf, James. P. (2003). Intrapersonal communication and internalization in the second language classroom. En A. Kozulin y B. Gindis (eds.), Vygotsky's educational theory in cultural context. Learning in doing (pp. 349-370). New York: Cambridge University Press.

McCarthy, D. (1983). M.S.C.A. Escalas de McCarthy de aptitudes y psicomotricidad para niños. Madrid: T.E.A.

Meisel, Jürgen. (2004). The bilingual child. En T.J. Bhatia y Richie (eds.), The handbook of bilingualism (pp. 91-113). Malden, MA: Blackwell.

Montero, Ignacio y De Dios, María Jesús. (2006). Vygotsky was right: An experimental approach to the study of the relationship between private speech and task performance. Estudios de Psicología, 27, 175-189.

Plumert, Jodie. M.; Ewert, K. y Spear, S. J. (1995). The early development of children's communication about nested spatial relations. Child Development, 66, 959-969.

Ramírez, Juan Daniel. (1992). The functional differentiation of social and private speech: A dialogic approach. En R. M. Díaz y L. E. Berk (eds.), Private speech: From social interaction to self-regulation (pp. 199-214). Hillsdale, NJ: Erlbaum.

Resches, Mariela y Pérez-Pereira, Miguel. (2007). Referential communication abilities and theory of mind development in preschool children. Journal of Child Language, 34, 21-52.

San Martín, Conchi. (2012). Aprendiendo a comunicar: Relaciones entre calidad comunicativa y habla privada. Infancia y Aprendizaje, 35 (3), 299-312.

San Martín, Conchi, Boada, Humbert y Forns, María. (2009). Private speech in the framework of referential communication. En A. Winsler, Ch. Fernyhough e I. Montero (eds.), Private speech, executive functioning, and the development of verbal self-regulation (pp. 121-133). Cambridge: Cambridge University Press.

San Martín, Conchi, Boada, Humbert y Feigenbaum, Peter. (2011). Private and inner speech and the regulation of social speech communication. Cognitive Development, 26 (3), 214-229. 
Saville-Troike, Muriel. (1988). Private speech: Evidence for second language learning strategies during the 'silent' period. Journal of Child Language, 15, 567-590.

Varenne, Christiane y Beaudichon, Janine. (1996). Régulation intrapersonnelle de la communication verbale chez l'enfant de 8-9 ans: Effets de paramètres contextuels. Enfance, 49, 411-430.

Vygotsky, Lev S. (1993). Pensamiento y lenguaje. En L. S. Vygotsky, Obras escogidas. Vol II. (pp. 11-348). Madrid: Aprendizaje Visor. (Trabajo original publicado en 1934).

Wertsch, James V. (1985). Vygotsky and the social formation of mind. Cambridge, MA: Harvard University Press.

Winsler, Adam, Fernyhough, Charles y Montero, Ignacio (eds.). (2009). Private speech, executive functioning, and the development verbal self-regulation. Cambridge: C.U.P.

Yelland, Gregory W., Pollard, Jacint y Mercuri, Anthony. (1993). The metalinguistic benefits of limited contact with a second language. Applied Psycholinguistics, 14, 423-444. 